\title{
Comparative study of Malaysian and Nigerian kaolin-based ceramic hollow fiber membranes for filtration application
}

\author{
Jamilu Usman a,b, Mohd Hafiz Dzarfan Othman a, ${ }^{a}$, Ahmad Fauzi Ismail a, Mukhlis A Rahman ${ }^{a}$, \\ Juhana Jaafar ${ }^{a}$, Tijjani Abdullahi ${ }^{\mathrm{c}}$ \\ a Advanced Membrane Technology Research Centre (AMTEC), School of Chemical and Energy Engineering, Faculty of Engineering, Universiti \\ Teknologi Malaysia, 81310 UTM Johor Bahru, Johor, Malaysia \\ b Department of Chemistry, Faculty of Science, Sokoto State University, P.M.B. 2134, Sokoto, Sokoto State, Nigeria \\ c Advanced Manufacturing and Material Centre (AMMC), Faculty of Mechanical and Manufacturing Engineering, Universiti Tun Hussein Onn, \\ Malaysia, 86400 Parit Raja, Batu Pahat, Johor, Malaysia \\ * Corresponding author: hafiz@petroleum.utm.my
}

\section{Article history}

Received 5 January 2019

Revised 14 February 2019

Accepted 11 March 2019

Published Online 15 April 2020

\section{Graphical abstract}

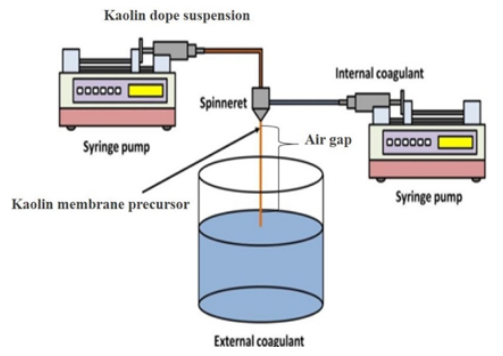

\begin{abstract}
Ceramic membrane has gained increasing interest in water filtration application due to its inherent characteristics. Low-cost clay materials are preferred to fabricate an efficient and cost-effective ceramic membrane. Among the ceramics, kaolin displays better mechanical, thermal, and chemical properties. However, natural properties of kaolin vary from different studies. Hence, cost-effective Nigeria (NK) and Malaysia (MK) kaolins were compared to study the fabrication of kaolin hollow fiber ceramic membrane for filtration application. The effects of kaolin loading concentration (34 and 37 wt. \%) and sintering temperature $\left(1200,1350,1400\right.$, and $\left.1500{ }^{\circ} \mathrm{C}\right)$ on kaolin membrane fabrication were also studied. XRF studies indicated that the hydroxyl silica and alumina compositions were $56.76 \mathrm{wt} . \%$ and $41.97 \mathrm{wt} \%$ for NK and $55.21 \mathrm{wt} . \%$ and $40.33 \mathrm{wt} \%$ for MK. MK exhibited intense kaolinite peak with a broad range of particle size distribution. The mechanical stability of kaolin ceramic membrane increased with the increase of sintering temperature and kaolin loading concentration. Membrane morphology also varied with MK and NK. Interestingly, 34wt\% kaolin at a sintered temperature of $1350{ }^{\circ} \mathrm{C}$ produced ceramic membrane with a high water flux. A similar trend was observed in both MK and NK, where the flux of $34 \mathrm{wt} \% \mathrm{MK}$ and NK are 565 and $460 \mathrm{~L} / \mathrm{m}^{2} \mathrm{~h}$, respectively.
\end{abstract}

Keywords: Ceramic hollow fiber membrane, kaolin, sintering, phase-inversion, water flux

\section{INTRODUCTION}

Alumina and zirconia are extensively used for fabrication of ceramic membrane for various filtration applications. However, these materials are relatively expensive. In the past five years, kaolin has been gathering more attention among researchers as the ceramic material for the manufacturing of membranes (Emani et al., 2014; Hubadillah et al., 2016a; Hubadillah et al., 2016b). Hydrophilicity is the main required property for filtration applications. Kaolin has the inherent property of hydrophilicity, good mechanical, thermal, and chemical stability (Mittal et al., 2011). These properties are required for the filtration membranes for better performance. Another, Kaolin is rich of hydrophilic group of silica and alumina and cost-effective material.

Phase inversion is a well-adopted method for the fabrication of polymeric asymmetric membranes. It is a complex phenomenon which relies on solvent, polymer, and non-solvent. A similar method is also extended for the fabrication of ceramic membranes. Flat sheet, tubular, and hollow fiber membranes are the different modules available in the commercial market. Fouling is the main drawback in membrane technology. Hollow fiber membrane shows better filtration performance as it delivers higher flux with better selectivity due to the higher surface area.
Lately, kaolin is used in fabrication of ceramic hollow fiber membranes for various filtration application such as oily wastewater treatment (Emani et al., 2014; Hubadillah et al., 2017), desalination (Kazemimoghadam et al., 2007), natural organic matter treatment (Shamsuddin et al., 2015) and gas separation (Hubadillah et al., 2016b). From the literature, kaolin has well-miscibility with solvents, additives, and binders. Kaolin is abundant in many countries, and the properties of kaolin also varied with respect to various geographical locations. The properties such as chemical composition, particle size and its distribution can influence the formation of membranes. The particle size are chief properties in the packing density of pores during membrane fabrication and sintering process (Hubadillah et al., 2016). Hence, two kaolins such as Nigerian kaolin (NK) and Malaysian kaolin (MK) were considered to compare the properties on membrane preparation and filtration applications. The main objectives of the study are: (i) Characterization of NK and MK, (ii) Fabrication of NK and MK ceramic hollow fiber membranes at two different loading concentrations of 34 and $37 \mathrm{wt} . \%$ and various sintering temperature of $1200,1350,1400$, and $1500{ }^{\circ} \mathrm{C}$, (iii) Water flux testing of $\mathrm{NK}$ and MK ceramic membranes. 


\section{EXPERIMENTAL}

\section{Materials}

The Malaysian kaolin clay powder samples were purchased from BG Oil Chem Sdn. Bhd. in Malaysia meanwhile the Nigerian kaolin clay was collected from Kankara local Government area of Katsina state in Nigeria. These samples were kept in the oven overnight before use to remove any trace amount of moisture. The solvent used was N2-methyl-2-pyrrolidone (NMP) because of its non-volatility in preparing the kaolin-based ceramic membrane (KBCM). Arlacel P135 (polyethyleneglycol 30-dipolyhydroxystearate) purchased from Uniqema was chosen as the dispersant. Polyethersulfone (PESF) purchased from Amoco chemical was used as the polymer binder during the suspension preparation.

\section{Kaolin-based hollow fiber membrane fabrication}

Prior to the membrane fabrication, the kaolin dope suspension was prepared according to Table 1 . The KBCM were prepared using the technique of phase-inversion and sintering of the membrane (Fig. 1). Oven-melted Arlacel P135 gel was dissolved in NMP by stirring, followed by the addition of kaolin clay powder. The mixture was milled in an NQM-2 planery ball mill for $48 \mathrm{~h}$ for complete homogeneity of the mixture. Next, PESf was added to the mixture as a binder and then milling was continued for another $48 \mathrm{~h}$. After that, the homogenized spinning suspension was degassed for 10 min using a vacuum pump, then the degassed suspension was transferred into a stainless-steel syringe for extrusion. The kaolin dope suspension was then extruded through the spinneret at a flow rate of $10 \mathrm{~mL} / \mathrm{min}$ and temperature of $25^{\circ} \mathrm{C}$. The bore fluid rate was delivered alongside the dope suspension by a syringe pump. The precursor membrane was then immersed in water for $24 \mathrm{~h}$ to ensure complete phase inversion after which were thoroughly washed with water. After the membrane was cut to the desired length, it was dried at ambient temperature for 2 to 3 days.

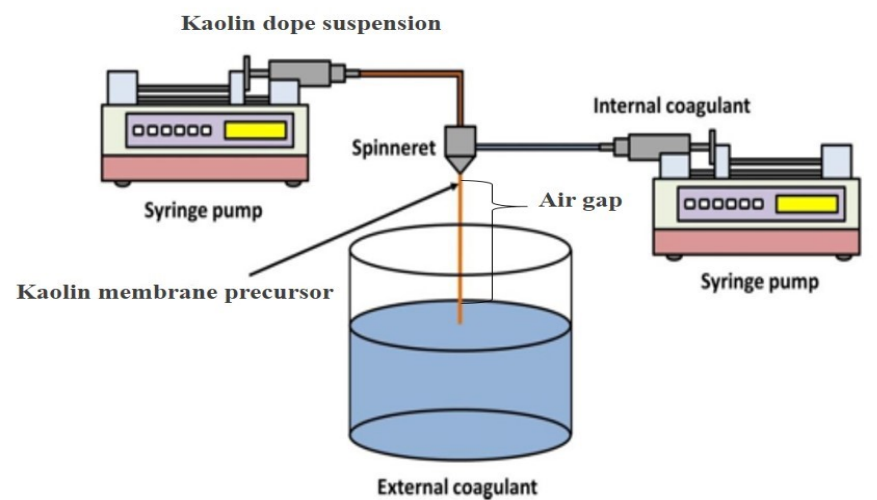

Fig. 1 Schematic diagram for phase-inversion and extrusion technique.

Table 1. The composition of kaolin dope suspension and water flux.

\begin{tabular}{|c|c|c|c|c|c|c|c|}
\hline \multirow[t]{2}{*}{ Membrane } & \multirow{2}{*}{$\begin{array}{c}\text { MK } \\
\text { (wt. \%) }\end{array}$} & \multirow[t]{2}{*}{ NK(wt.\%) } & \multirow{2}{*}{$\begin{array}{c}\text { PESf } \\
\text { (wt. \%) }\end{array}$} & \multirow{2}{*}{$\begin{array}{c}\text { NMP } \\
\text { (wt. \%) }\end{array}$} & \multicolumn{3}{|c|}{ flux $\left(L / m^{2} h\right)$} \\
\hline & & & & & $1350^{\circ} \mathrm{C}$ & $1400^{\circ} \mathrm{C}$ & $1500^{\circ} \mathrm{C}$ \\
\hline MK-37 & 37 & - & 5 & 57 & 275.5 & 155.50 & 110.50 \\
\hline NK-37 & - & 37 & 5 & 57 & 210.29 & 144.27 & 76.93 \\
\hline MK-34 & 34 & - & 5 & 60 & 565.06 & 268.07 & 150.63 \\
\hline NK-34 & - & 34 & 5 & 60 & 460.56 & 184 & 124.02 \\
\hline
\end{tabular}

The dried membrane precursor was sintered at different sintering temperatures between 1200 to $1500{ }^{\circ} \mathrm{C}$ in the tubular furnace (XY1700 MAGNA). The temperature was maintained for 2 hours from room temperature to $600{ }^{\circ} \mathrm{C}$ at a heating rate of $2{ }^{\circ} \mathrm{C} / \mathrm{min}$ to remove the residual liquid and to add organic binder and dispersant. Then, the furnace temperature was further increased to the target temperature at a heating rate of $5{ }^{\circ} \mathrm{C} / \mathrm{min}$ and was then kept constant for 5 hours.
Finally, the furnace temperature was reduced to room temperature at a heating rate of $5{ }^{\circ} \mathrm{C} / \mathrm{min}$.

\section{RESULTS AND DISCUSSION}

\section{Characteristics of raw Kaolin powders}

Fig. 2 shows the particle size distribution of the MK and NK powders. From the figure, unimodal distribution can be observed on both MK and NK. In general, the higher particle size distribution of ceramic leads to less packing structure and resulting in the production of the membrane with more porous structures (Hubadillah et al., 2016a). The size ranges of NK and MK were found to be from 700 to $2000 \mathrm{~nm}$ and 950 to $2700 \mathrm{~nm}$, respectively. The wide range of particle size of MK is presumably due to the presence of mixture oxides which composed by kaolinite and some impurities.

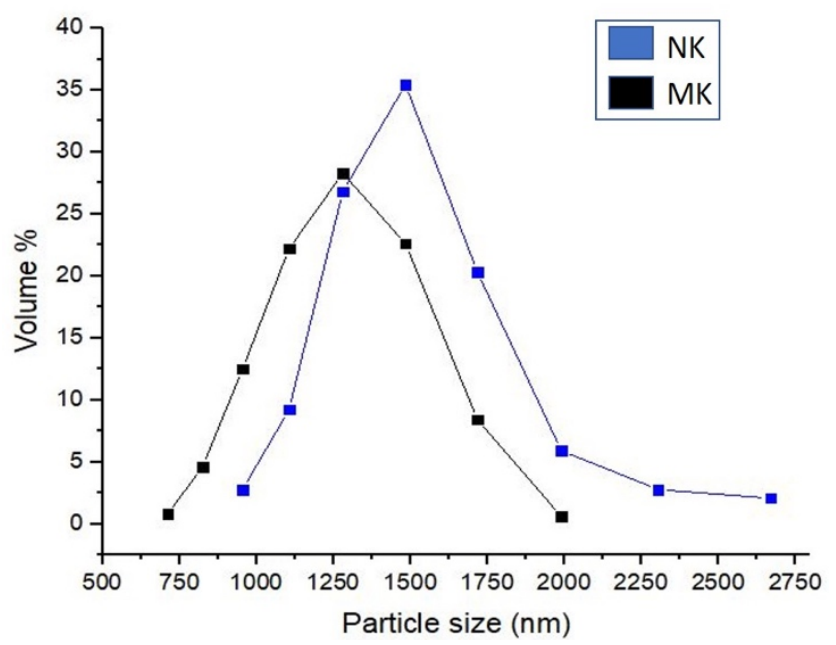

Fig. 2 Particle size distribution of the two-country kaolin sample.

From XRD result shown in Fig. 3, the predominant phase of kaolinite is observed with minor quartz impurity. Both kaolin diffraction pattern agrees with KAOLINITE JCPDS no. 01-089-6538 database and the intensity of kaolinite is found to be higher for MK. Also, the patterns are consistent with earlier literature (Nandi et al., 2009; Zhu, et al., 2010). Moreover, metal oxides percentage by weight composition using XRF analysis for MK and NK are $55.21 \%$ of $\mathrm{SiO}_{2}$ and $40.33 \%$ of $\mathrm{Al}_{2} \mathrm{O}_{3}$ for $\mathrm{MK}$ and $56.76 \%$ of $\mathrm{SiO}_{2}$ and 41.97 $\%$ of $\mathrm{Al}_{2} \mathrm{O}_{3}$ for $\mathrm{NK}$.

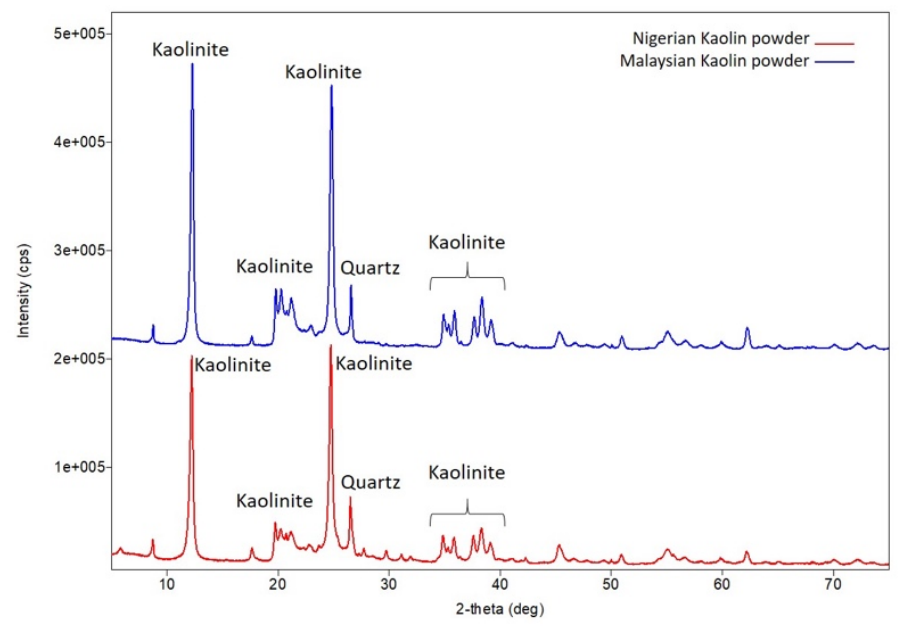

Fig. 3 XRD patterns of the raw kaolin samples.

Thermogravimetric analysis was also performed on the two kaolin samples to identify the thermal stability. Fig. 4 shows the TGA and 
DTA of MK and NK powder samples. The total weight loss of MK was higher (15.9\%) than NK. The TGA of MK possesses two distinct stages due to its high dehydroxylation of the kaolinite. This results also coincide with DTA endothermic peak at $510{ }^{\circ} \mathrm{C}$ for both samples (Fig. 4). Overall, the two types of kaolin hold similar crystallite structure with different thermal and pore size distribution properties. The influence of the two types of kaolin on ceramic hollow fiber membrane for fabrication and characterization are discussed in following sections.

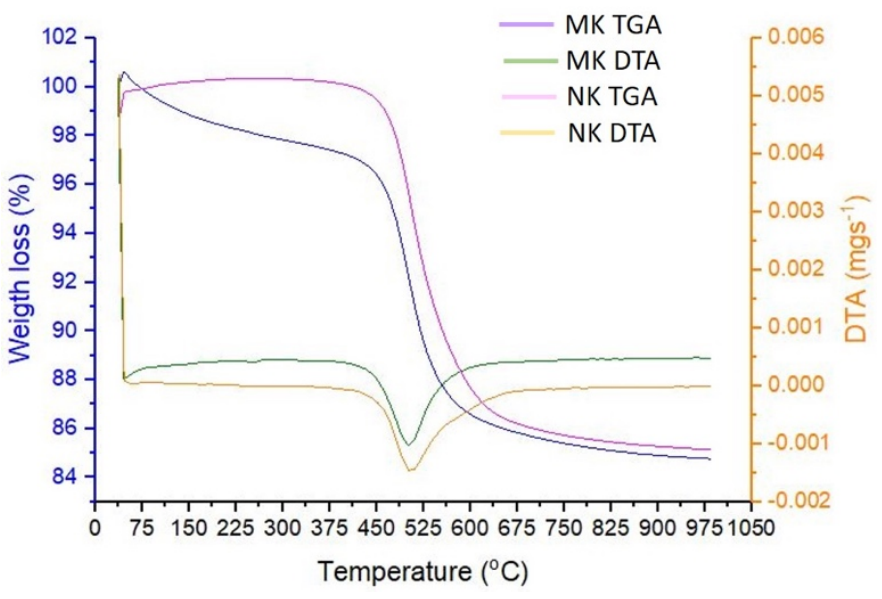

Fig. 4 TGA and DTA of the two kaolin samples.

\section{Characteristics of sintered hollow fibre membranes}

Fig. 5 shows the effect of sintering temperature on the mechanical strength of the MK and NK membranes. The desired property of ceramic membrane should have the higher mechanical strength for pressure-driven operation.

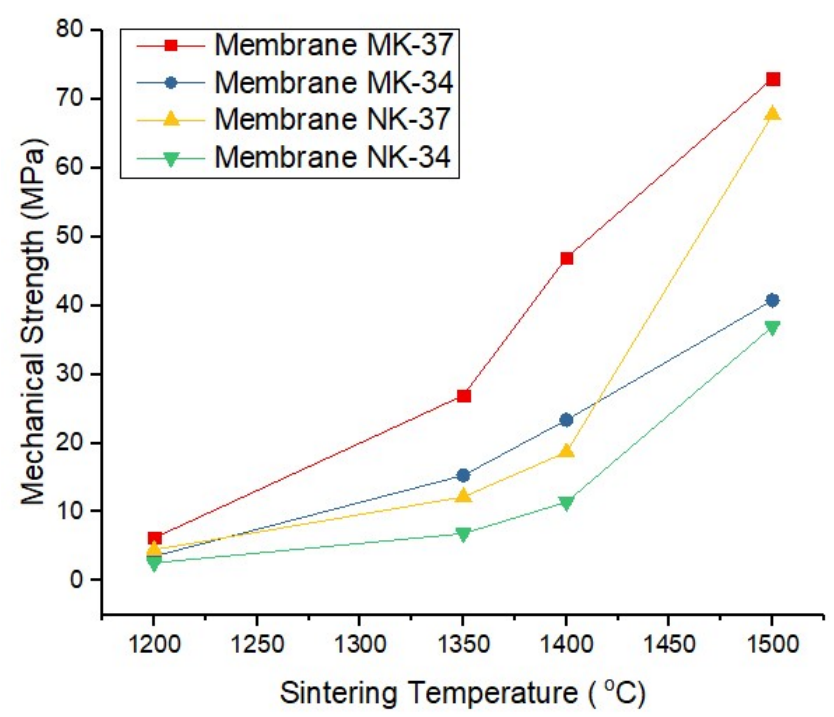

Fig. 5 Mechanical strength of the membranes.

From Fig. 5, the mechanical strength of the membrane increases with the increase of sintering temperature from 1200 to $1500{ }^{\circ} \mathrm{C}$. The higher mechanical strength was observed for ceramic hollow fiber membrane fabricated at a sintering temperature of $1500{ }^{\circ} \mathrm{C}$. Among the membranes, MK-37 hold higher mechanical strength of $73 \mathrm{MPa}$ for $1500{ }^{\circ} \mathrm{C}$ sintered made kaolin membrane. MK showed resilient in both the loading concentrations of 34 and $37 \mathrm{wt} \%$ of ceramic hollow fiber membranes. It is mainly due to the particle size and distribution of MK. During sintering, MK particles are arranged into formation of ordered pore structure which eventually leads to formation of defectfree stable kaolin membrane. As can be seen in Fig 5, two distinct phases were noticed. The mechanical stability increases slowly at the sintering temperature range of 1200 to $1350{ }^{\circ} \mathrm{C}$. The mechanical strength increases rapidly from 1400 to $1500{ }^{\circ} \mathrm{C}$ for both 34 and 37 $w t \%$ loading concentrations. Furthermore, the increase in loading of kaolin concentration increases the mechanical stability in both NKand MK-based hollow fiber membranes. This is due to the formation of high packing density of kaolin particles in hollow fiber membranes.

Fig. 6 and 7 show the cross-section morphology of kaolin hollow fiber membranes sintered at various temperatures starting from 1200 to $1500{ }^{\circ} \mathrm{C}$. It is worth mentioning that the morphology of the membrane fibers sintered at $1200{ }^{\circ} \mathrm{C}$ could not be measured as they were too brittle and subjected to failure. All membranes exhibit a typical asymmetric structure consisting of macro-voids on the inner side and relatively dense sponge-like structures on the outer side. The cross-section morphology of lower NK-34 and MK-34 membranes display a porous structure with irregular arrangement. It is due to the lower concentration of kaolin which leads to instantaneous formation of membrane. However, dense pores were observed in case of NK-37 and MK-37 kaolin membranes. It is mainly due to the delay in the exchange rate of solvent and non-solvent during phase inversion. The membrane formation was also varied with the effect of sintering temperature and it is evident in cross sectional analysis. The thick skin layer observed in the higher sintering temperature made ceramic membranes. This is owing to the increase of sintering temperature which allows the kaolin to form interconnected arrangement. In terms of membrane microstructures, it can be observed that there is less formation of interconnected particles at $1350{ }^{\circ} \mathrm{C}$ sintering temperature while at an increased temperature, there is increase in interconnected particles which result in compact microstructures and become more homogenous at the highest temperature $\left(1500{ }^{\circ} \mathrm{C}\right)$. The result is comparable with the report of Silva et al. (2015) that an increase in sintering temperature leads to membrane densification and thus increases the mechanical strength.

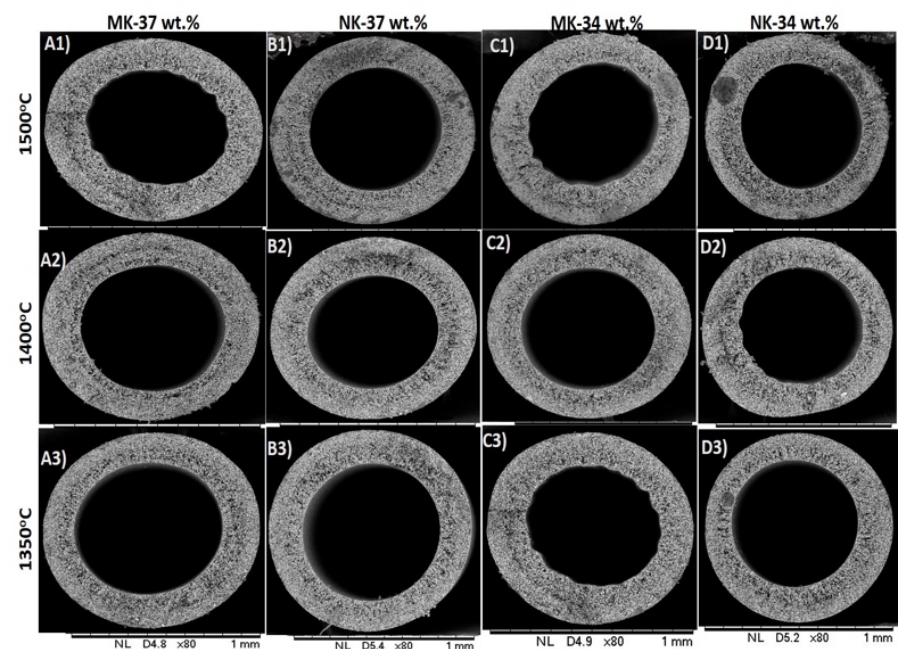

Fig. 6 Overall cross-section SEM images of the kaolin membranes at different kaolin powder contents (MK-37 \& 34 wt. \%; NK-37 \& 34 wt. \%) and sintering temperatures $\left(1350,1400,1500{ }^{\circ} \mathrm{C}\right)$.

Fig. 7 shows an increase magnification $(50$ and $200 \mu \mathrm{m})$ of the membrane SEM images where the presence of macro-voids regions are seen in all membranes. However, the percentage of the macrovoids increase with an increase in sintering temperature. As can be seen, membranes sintered at $1350{ }^{\circ} \mathrm{C}$ display less macro-voids and higher spread out of sponge-like structures. The presence of the macro-void structure could be due the interfacial instabilities between the kaolin dope suspension and the coagulant which come in contact during phase inversion process. In terms of membrane microstructures, it can be observed that there is less formation of interconnected particles at $1350{ }^{\circ} \mathrm{C}$ sintering temperature while at an increased temperature, there is an increase in interconnected particles which result in compact microstructures and become more homogenous at the highest temperature $\left(1500^{\circ} \mathrm{C}\right)$. 


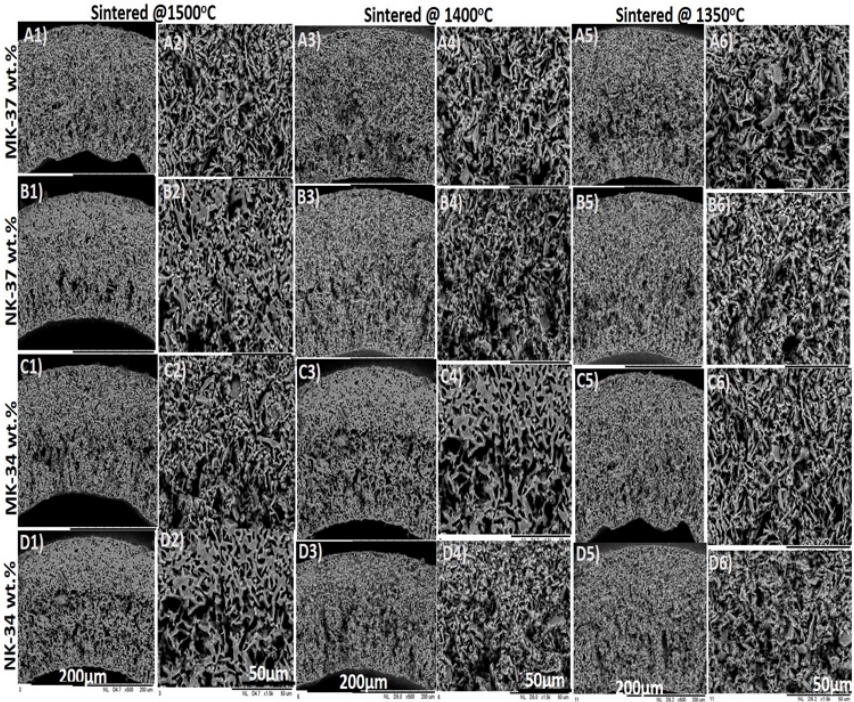

Fig. 7 Magnified cross section of the kaolin membranes at different loading concentrations and sintering temperatures.

\section{Microfiltration performance}

Fig. 9 shows the water flux data with respect to different sintering temperatures of NK- and MK-based ceramic microfiltration membranes. The higher water fluxes of 565.06 and $460.56 \mathrm{~L} / \mathrm{m}^{2} \mathrm{~h}$ were observed for $1350{ }^{\circ} \mathrm{C}$ sintered temperature of MK-34 and NK-34 based ceramic microfiltration membrane respectively. It can be observed that flux decreases with the increase of sintering because increasing the sintering temperature leads to densification of the membrane and which further causes the membrane pore to shrink. Overall, membrane fabricated using MK exhibits higher mechanical stability with better water flux rate over the NK membrane. However, the NK has proved to possess attractive qualities for ceramic membrane application, which can be improved with further studies.

\section{CONCLUSION}

In this study, ceramic hollow fiber membrane from Malaysia and Nigeria kaolins have been successfully prepared through combined phase-inversion and sintering techniques. The kaolin loading concentrations were varied from 34 to $37 \mathrm{wt}$. \%. The membranes sintering process was carried out at a temperature range of 1200 to $1500{ }^{\circ} \mathrm{C}$. It can be observed from the results that the properties of the two-country kaolin are similar in crystallinity and chemical composition. Also, at the studied sintering temperatures (1350-1500 ${ }^{\circ} \mathrm{C}$ ), both types of kaolin produced defect-free ceramic membrane with porous asymmetric structure. The wider distribution of particle size was observed in MK. In the membrane characterization studies, the higher mechanical strength of $73 \mathrm{MPa}$ was observed for $37 \mathrm{wt} \%$ MK ceramic hollow fiber membranes compared to other membranes. It indicates that the MK has good miscible properties with solvents and additives. Noted that the high water flux of $565 \mathrm{~L} / \mathrm{m}^{2} \mathrm{~h}$ for $34 \mathrm{wt} \%$ MK ceramic hollow fiber membranes is due to the wider range of MK particle size distribution which enables the formation of formation of ordered pores under the sintering process.

\section{ACKNOWLEDGEMENT}

The authors gratefully acknowledge the financial support provided from the Ministry of Education Malaysia under the Higher Institution Centre of Excellence Scheme (Project Number:
R.J090301.7846.4J194) and Universiti Teknologi Malaysia under the Research University Grant Tier 1 (Project Number: Q.J130000.2546.16H40). The authors would also like to thank Research Management Centre, Universiti Teknologi Malaysia for the technical support given. Additionally, the authors would like to thank Petroleum Technology Development Fund (PTDF) of Nigeria for the substantial financial support of the study.

\section{REFERENCES}

Emani, S., Uppaluri, R., \& Purkait, M. K. (2014). Cross flow microfiltration of oil-water emulsions using kaolin based low cost ceramic membranes. Desalination, 341, 61-71.

Hubadillah, S. K., Harun, Z., Othman, M. H. D., Ismail, A. F., \& Gani, P. (2016a). Effect of kaolin particle size and loading on the characteristics of kaolin ceramic support prepared via phase inversion technique. Journal of Asian Ceramic Societies, 4(2), 164-177.

Hubadillah, S. K., Harun, Z., Othman, M. H. D., Ismail, A. F., Salleh, W. N. W., Basri, H., ... \& Gani, P. (2016b). Preparation and characterization of low cost porous ceramic membrane support from kaolin using phase inversion/sintering technique for gas separation: Effect of kaolin content and non-solvent coagulant bath. Chemical Engineering Research and Design, 112, 24-35.

Hubadillah, S. K., Othman, M. H. D., Harun, Z., Ismail, A. F., Rahman, M. A., Jaafar, J., ... \& Mohtor, N. H. (2017). Superhydrophilic, low cost kaolinbased hollow fibre membranes for efficient oily-wastewater separation. Materials Letters, 191, 119-122.

Kazemimoghadam, M., \& Mohammadi, T. (2007). Synthesis of MFI zeolite membranes for water desalination. Desalination, 206(1-3), 547-553.

Kumar, R. V., Ghoshal, A. K., \& Pugazhenthi, G. (2015). Elaboration of novel tubular ceramic membrane from inexpensive raw materials by extrusion method and its performance in microfiltration of synthetic oily wastewater treatment. Journal of Membrane Science, 490, 92-102.

Li, K. (2007). Ceramic membranes for separation and reaction. John Wiley \& Sons.

Madaeni, S. S., Monfared, H. A., Vatanpour, V., Shamsabadi, A. A., Salehi, E., Daraei, P., ... \& Khatami, S. M. (2012). Coke removal from petrochemical oily wastewater using $\gamma-\mathrm{Al}_{2} \mathrm{O}_{3}$ based ceramic microfiltration membrane. Desalination, 293, 87-93.

Mittal, P., Jana, S., \& Mohanty, K. (2011). Synthesis of low-cost hydrophilic ceramic-polymeric composite membrane for treatment of oily wastewater. Desalination, 282, 54-62.

Nandi, B. K., Goswami, A., \& Purkait, M. K. (2009). Adsorption characteristics of brilliant green dye on kaolin. Journal of Hazardous Materials, 161(1), 387-395.

Rekik, S., Bouaziz, J., Deratani, A., \& Baklouti, S. (2016). Development of an asymmetric ultrafiltration membrane from naturally-occurring kaolin clays: Application to the cuttlefish effluents treatments. International Journal of Membrane Science and Technology, 6(3), 1000159.

Shamsuddin, N., Das, D. B., \& Starov, V. M. (2015). Filtration of natural organic matter using ultrafiltration membranes for drinking water purposes: circular cross-flow compared with stirred dead-end flow. Chemical Engineering Journal, 276, 331-339.

Silva, M. C. D., Lira, H. D. L., Lima, R. D. C. D. O., \& Freitas, N. L. D. (2015). Effect of sintering temperature on membranes manufactured with clays for textile effluent treatment. Advances in Materials Science and Engineering, 2015.

Vasanth, D., Pugazhenthi, G., \& Uppaluri, R. (2013). Cross-flow microfiltration of oil-in-water emulsions using low cost ceramic membranes. Desalination, 320, 86-95.

Yang, T., Ma, Z. F., \& Yang, Q. Y. (2011). Formation and performance of Kaolin/MnO2 bi-layer composite dynamic membrane for oily wastewater treatment: Effect of solution conditions. Desalination, 270(1-3), 50-56.

Yeom, H. J., Kim, S. C., Kim, Y. W., \& Song, I. H. (2016). Processing of alumina-coated clay-diatomite composite membranes for oily wastewater treatment. Ceramics International, 42(4), 5024-5035.

Zhu, H. Y., Jiang, R., \& Xiao, L. (2010). Adsorption of an anionic azo dye by chitosan/kaolin $/ \gamma$-Fe2O3 composites. Applied Clay Science, 48(3), 522526. 